\title{
Optimization Design of I-Type Plastic Extrusion Die Based on Flow Balance
}

\author{
Hai-Feng Fang ${ }^{*}, 1,2$, Li-Hua Cai ${ }^{1,2}$, Ming-Qiang Wang $^{1}$, Qi Wang ${ }^{1}$ and De-Fang $\mathrm{He}^{3}$ \\ ${ }^{1}$ Mechatronics \& Automotive Engineering School, Jiangsu University of Science \& Technology, Jiangsu Zhangjiagang, \\ 215600, China \\ ${ }^{2}$ Suzhou Institute of Technology, Jiangsu Zhangjiagang, 215600, China \\ ${ }^{3}$ Zhangjiagang Beier Machinery CO., LTD. Jiangsu Zhangjiagang, 215600, China
}

\begin{abstract}
With the I-type plastic extrusion die for example, the advantages and disadvantages between the traditional design method and optimization design method were compared. The design was studied via finite element numeric analysis combined with optimization, whose objective was the equal average flow velocity of each sub-field of profile cross section at extrusion die. And the optimization design was studied by tacking the thickness of the entrance of transition section and the sectional dimension of forming section as the design variables. An example was provided to illustrate the optimization method proposed above. Results showed that the flow nonuniformity index could be reduced almost $9 \%$ and the mean flow velocity could be improved $28 \%$ by optimizing the design variables such as the thickness of the entrance of transition section and the sectional dimension of forming section.
\end{abstract}

Keywords: Extrusion die, flow balance, I-type, numeric analysis, optimization design.

\section{INTRODUCTION}

Plastic extrusion die design is a very important part of the extrusion molding technology, which influences many factors such as the die cost, productivity, die life, product accuracy and production cycle. Therefore, it is extremely essential to study the plastic extrusion die, especially the design of its transition section and forming section. The extrusion forming process of plastic profiles is a complex continuous nonlinear dynamic process involved thermodynamics, fluid mechanics, organic chemistry, mechanics and other disciplines, making the extrusion die design more difficult than other forming mold design [1-6].

The mold need be tested and repaired repeatedly in the traditional plastic extrusion die manufacture, which require skillful technical talents and a mount of human and material resource. With the development of modern computer, lots of fluid analysis software products have appeared, which could optimize the relevant parameters before the plastic extrusion die manufacture, simplifying the manual testing and repairing procedures.

Based on the influence analysis of the structure parameters on the extrusion flow, the mathematical model was established and studied via finite element numeric analysis combined with optimization, whose objective was the equal average flow velocity of each sub-field of profile cross section at extrusion die. The detailed optimization process was provided by an example, verifying the correctness and validity of the proposed method.

\section{TRADITIONAL PLASTIC EXTRUSION DIE ANALYSIS}

In traditional design, the plastic extrusion die runner was designed to streamline by experience, avoiding sudden changes and stagnations. However, it was unable to ensure of the flow uniformity of the outlet. With the development of the fluid simulation technology, we could evaluate the mold design with the help of the new numerical simulation technology. The problems and deficiencies could be found in the design process, improving the reliability and economy of the mold design.

\subsection{Mathematical Model}

Based on the production practice experience, material characteristic and the specific process conditions of the plastic extrusion, the instructions in this section assume the following: steady laminar flow, wall adhesion, regardless of the inertia force and gravity, isothermal flow, melt incompressibility.

Based on the law of mass conservation, momentum conservation and energy conservation, the continuity equation, momentum equations, and constitutive equations were established as follows $[7,8]$.

The continuity equation:

$\frac{\partial v_{x}}{\partial x}+\frac{\partial v_{y}}{\partial y}+\frac{\partial v_{z}}{\partial z}=0$ 
The momentum equations:

$$
\begin{aligned}
& \frac{\partial P}{\partial x}=\eta\left(\frac{\partial^{2} v_{x}}{\partial x^{2}}+\frac{\partial^{2} v_{x}}{\partial y^{2}}+\frac{\partial^{2} v_{x}}{\partial z^{2}}\right) \\
& \frac{\partial P}{\partial y}=\eta\left(\frac{\partial^{2} v_{y}}{\partial x^{2}}+\frac{\partial^{2} v_{y}}{\partial y^{2}}+\frac{\partial^{2} v_{y}}{\partial z^{2}}\right) \\
& \frac{\partial P}{\partial z}=\eta\left(\frac{\partial^{2} v_{z}}{\partial x^{2}}+\frac{\partial^{2} v_{z}}{\partial y^{2}}+\frac{\partial^{2} v_{z}}{\partial z^{2}}\right)
\end{aligned}
$$

The constitutive equations:

$$
\tau=\eta(\dot{\gamma}) \cdot \dot{\gamma}=k \cdot \dot{\gamma}^{n-1} \cdot \dot{\gamma}
$$

In the above equations, the velocity components in $x, y$ and $z$ direction are expressed as $v_{x}, v_{y}$ and $v_{z}$ respectively; $P$ is the static pressure; $\eta$ is the viscosity; $\tau$ is the shearing stress; $\dot{\gamma}$ is the shearing rate; $K$ is the consistency coefficient; $n$ is the power exponent.

\subsection{Finite Element Model Establishment of Die Runner}

The extrusion die runner was divided into 3 sections, which are transportation section, transition section and forming section. Establish the finite element model of the die runner and divide it into small grids, which includes 295649 three-dimensional elements, shown in Fig. (1).

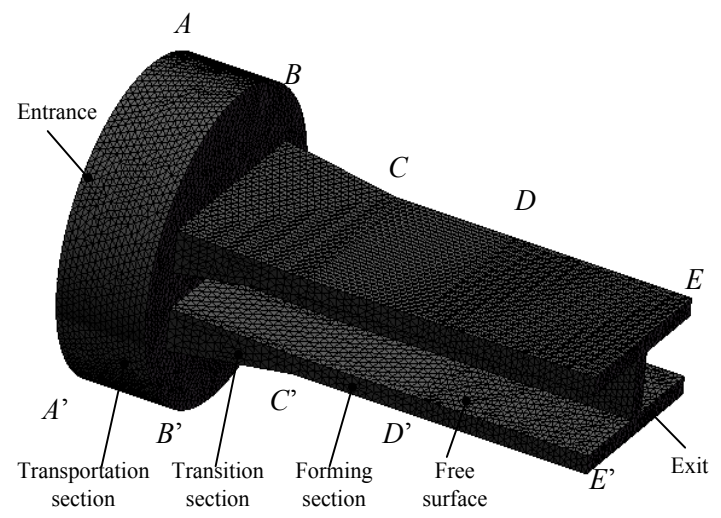

Fig. (1). Finite element model of die runner.

Based on the production practice experience and the fundamental assumption of the extrusion forming, the boundary conditions were defined as follows [9]: $A A^{\prime}$ is the entrance of the solution domain. At the entrance, the melt subjects to a constant normal force and the flow is 3000 $\mathrm{mm}^{3} / \mathrm{s}$. $E E^{\prime}$ ' is the exit of the solution domain. At the exit, the melt bears no traction and $v_{\mathrm{s}}, F_{\mathrm{n}}$ both equal 0 . At the adhesion section, the melt sticks to the wall while flowing in the die runner. For the adhesion section, $v_{\mathrm{n}}$ and $v_{\mathrm{s}}$ both equal 0 . For the free surface, $F_{\mathrm{n}}$ and $v_{\mathrm{n}}$ both equal 0 .

The sectional dimension of forming section was shown in Fig. (2). Assume that the length $l$, the width $t$ and the corresponding transition section entrance thickness $t_{1}$ of the upper and lower horizontal parts were equivalent, respectively. $h, b$ and $b_{1}$ were the length, the width and the corresponding transition section entrance thickness of the middle vertical part, respectively. In this calculation example, $l$ is $60 \mathrm{~mm}, t$ is $6 \mathrm{~mm}, t_{1}$ is $12 \mathrm{~mm}, h$ is $20 \mathrm{~mm}, b$ is $6 \mathrm{~mm}, b_{1}$ is $12 \mathrm{~mm}$.

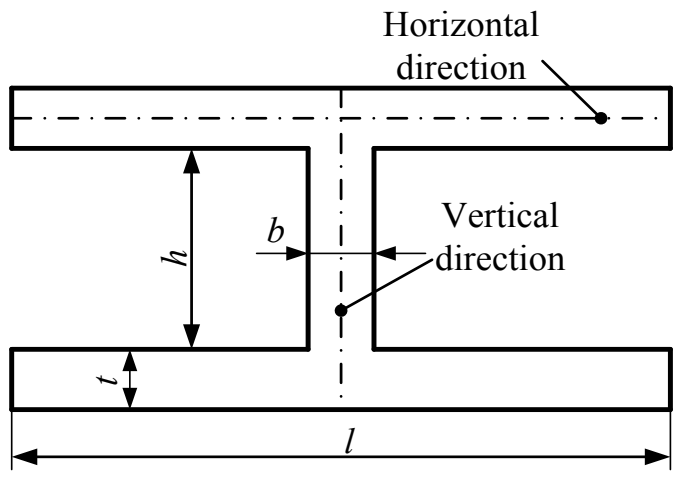

Fig. (2). Sectional dimension of forming section.

\subsection{Problem Analysis of Traditional Plastic Extrusion Die}

Based on the above model and boundary conditions, we could obtain the velocity profile for the outlet of the die, shown in Fig. (3). The velocity at the central connection was $24 \mathrm{~mm} / \mathrm{s}$, the velocity at the I-type corner was $15 \mathrm{~mm} / \mathrm{s}$, and the velocity at the side wall was $10 \mathrm{~mm} / \mathrm{s}$. Considering the above analysis of Fig. (3), the flow velocity distribution of each sub-field of profile cross section at extrusion die was comparatively uneven. Therefore, if the die structure design violated the flow rate balance principle, the profile extrudate would twist and deform, even cause wrinkles or fracture, while leaving the extrusion die [10-13]. In order to obtain a balance of extrusion die flow speed, the trial-and-error method was traditionally adopt in the optimization of the sectional dimension of forming section and the geometric outline of transition section. However, we could adopt the advanced optimization technique to optimize the geometric parameters of the extrusion die, improving the reliability and economy of the mold design.

\section{OPTIMIZATION MODEL ESTABLISHMENT}

Many scholars have done a lot of research on the extrusion die optimization. Lots of new ideas about the extrusion die design theory, design method and improvement were put forward. But most of those researches were for a particular type of mould or based on some simple flow channel section, such as round, rectangular and circular, etc. Those extrusion die optimization design based on the analytical method could not be applicable to the complex flow channel section.

To analyze the flow state of the plastic melt in the extrusion die was the primary task to optimize the die runner. The optimization objective was to achieve the minimum mean square error of each sub-field of profile cross section at extrusion die. It made for obtaining the plastic products with more uniform mechanical properties but less twist, deformation, wrinkle and fracture. In this 


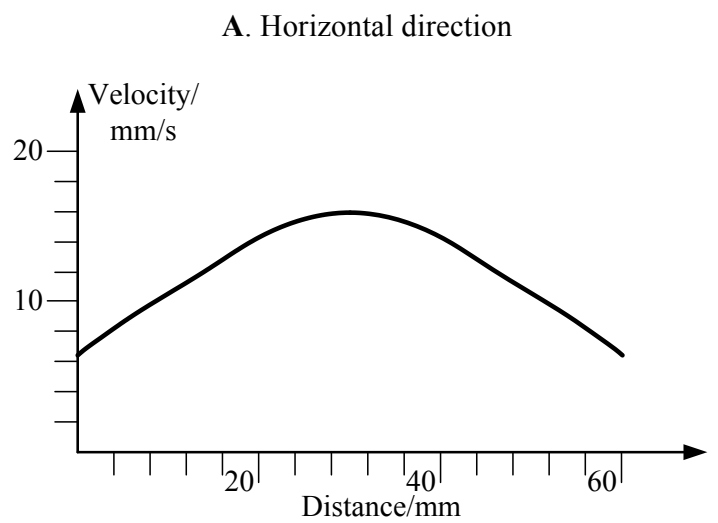

B. Vertical direction

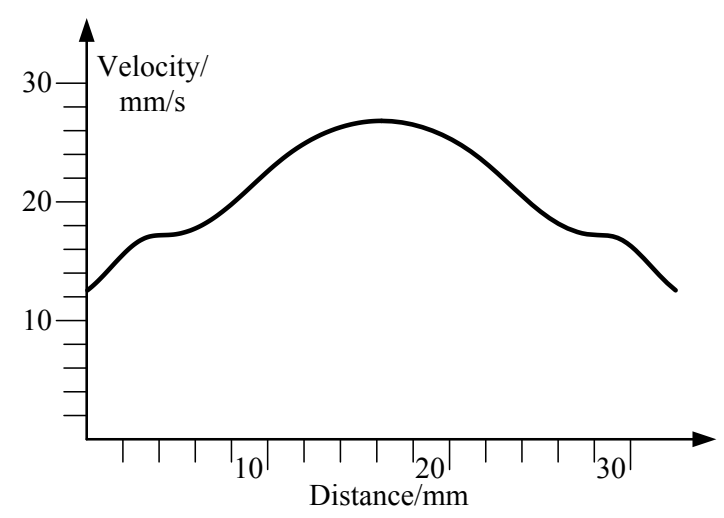

Fig. (3). Velocity profile for the outlet of the die.

paper, the finite element mothed was adopted to analyze the I-type plastic extrusion die. The mathematic model was established, as shown in formula 6, whose optimization objective function was the mean square error of the flow velocities of each cell nodes at the die exit cross profile [14$18]$.

$\min f(\varphi)=\int\left[\frac{v_{x y}(\varphi)}{\bar{v}}-1\right]^{2} d x d y=\sum_{i=1}^{N}\left[\frac{v_{i}(\varphi)}{\bar{v}}-1\right]^{2}$

where, $\varphi$ is the set of design variables, which includes the length $l$, the width $t$, the corresponding transition section entrance thickness $t_{1}$ of the horizontal parts, and the length $h$, the width $b$ and the corresponding transition section entrance thickness $b_{1}$ of the middle vertical part. Table 1 shows the scopes of the above design variables. $f(\varphi)$ is the mean square error of the flow velocities, which is the objective function. $N$ is the count of the cell nodes at the die exit cross profile. $\bar{v}$ is the average velocity at the die exit cross profile. $v_{i}(\varphi)$ is the velocity of node $i$ at the die exit cross profile.

The thickness of the entrance of transition section and the sectional dimension of forming section was selected as the design variables, which had great influence upon the plastic extrusion flow. The flow equilibrium could be achieved by optimizing these above design variables to balance the melt flow resistance of each sub-field.

The optimum path of the die runner was shown in Fig. (4).

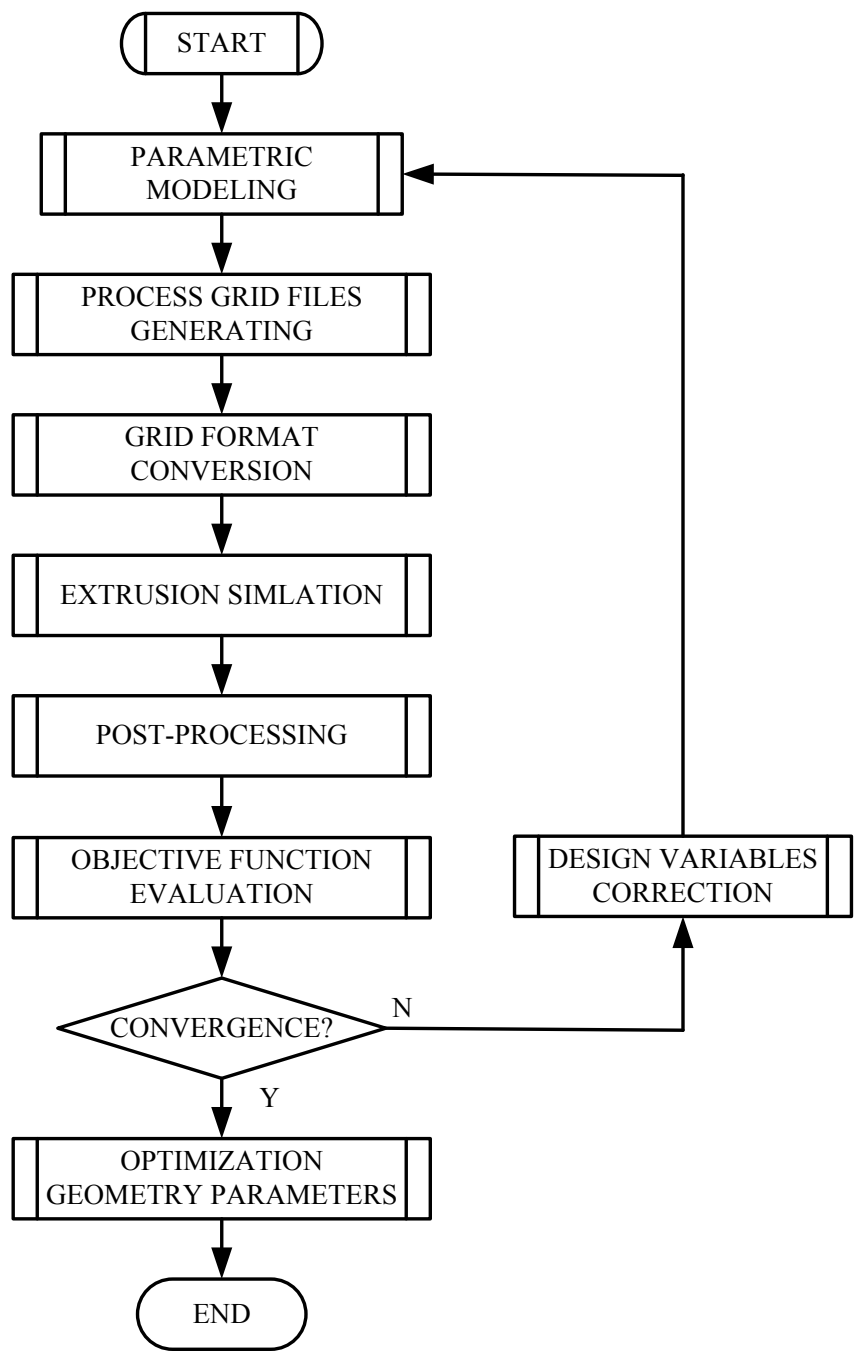

Fig. (4). Optimum path of the die runner.

\section{OPTIMIZATION RESULT ANALYSIS}

The initial port design's unit was divided reasonably. And the boundary conditions, initial conditions, material physical parameters and process parameters was introduced into the optimization. At the end of the finite element solution, the state variables and the objective function value of optimization could be extracted from the finite element calculation results in the post-processing module.

The scopes of design variables in the optimization was shown in Table 1. After the optimization, the velocity profile for the outlet of the die was obtained, shown in Fig. (5). And the optimization results were shown in Table 2.

As shown in the above charts, it was found that the dimension of each sub-field could reach a better proportion and the melt flow resistance of each sub-field could be balanced by optimizing the thickness of the entrance of transition section and the sectional dimension of forming section.

The flow equilibrium of the die exit was improved and the flow nonuniformity index was reduced almost $9 \%$. And the mean flow velocity was improved $28 \%$, from 13.52 $\mathrm{mm} / \mathrm{s}$ up to $17.31 \mathrm{~mm} / \mathrm{s}$, which could completely satisfy different engineering applications. 
A. Horizontal direction

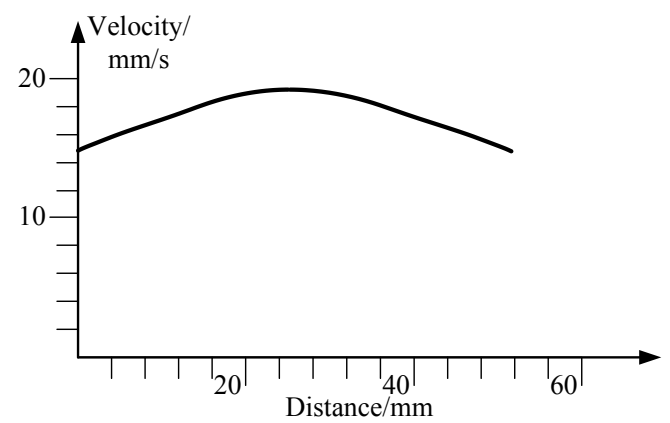

B. Vertical direction

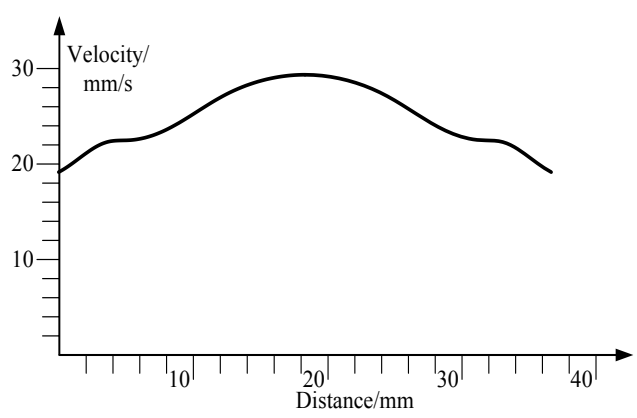

Fig. (5). Velocity profile for the outlet of the die after the optimization.

Table 1. Scopes of design variables.

\begin{tabular}{|c|c|}
\hline Design Variables & Scope/mm \\
\hline \hline$l$ & $50-70$ \\
\hline$t$ & $4-8$ \\
\hline$t_{1}$ & $8-16$ \\
\hline$h$ & $12-28$ \\
\hline$b$ & $4-8$ \\
\hline$b_{1}$ & $8-16$ \\
\hline
\end{tabular}

Table 2. Optimization design results.

\begin{tabular}{|c|c|c|}
\hline Design Variables & Initial Design & Optimization Design \\
\hline \hline$l / \mathrm{mm}$ & 60 & 52.32 \\
\hline$t / \mathrm{mm}$ & 6 & 7.58 \\
\hline$t_{1} / \mathrm{mm}$ & 12 & 14.21 \\
\hline$h / \mathrm{mm}$ & 20 & 22.56 \\
\hline$b / \mathrm{mm}$ & 6 & 4.86 \\
\hline$b_{1} / \mathrm{mm}$ & 12 & 8.75 \\
\hline Exit mean flow velocity $/ \mathrm{mm} \cdot \mathrm{s}^{-1}$ & 13.52 & 17.31 \\
\hline Nonuniformity index $/ \%$ & 12.36 & 3.12 \\
\hline
\end{tabular}

\section{CONCLUSION}

In this paper, the advantages and disadvantages between the traditional design method and optimization design method were compared. Further more, the mathematical model was established and studied via finite element numeric analysis combined with optimization, whose objective was the minimum mean square error of each subfield of profile cross section at extrusion die. And the thickness of the entrance of transition section and the sectional dimension of forming section was selected as the design variables.

The detailed optimization process was provided by an example. The optimization results showed that the flow equilibrium of the die exit was improved and the flow nonuniformity index was reduced almost $9 \%$, and the mean flow velocity was improved $28 \%$.

\section{CONFLICT OF INTEREST}

The authors confirm that this article content has no conflict of interest.

\section{ACKNOWLEDGEMENTS}

The financial supports from Natural Science Foundation of the Jiangsu Higher Education Institutions of China (Grant No. 14KJD440001), Zhangjiagang Science and Technology Support Program (Grant No. ZKG1314) and Youth Science Fund of Jiangsu University of Science \& Technology are greatly appreciated.

The authors would like to thank the engineering technicians of the Zhangjiagang Beier Machinery LTD. for their devoted help.

\section{REFERENCES}

[1] S. S. Akhtar, and A. F. M. Arif, "Effect of profile corners on the nitriding treatment of AISI H13 hot extrusion dies", J. Manuf. Sci. Eng. Trans. ASME, vol. 2, pp. 91-108, 2014.

[2] Z. Zhang, "Twinning related plastic mechanism of a magnesium alloy at a high strain stage of ambient sheathextrusion", Mater. Lett., pp. 79-83, 2014.

[3] A. Babaei, M. M. Mashhadi, and H. Jafarzadeh, "Tube cyclic expansion-extrusion (TCEE) as a novel severe plastic deformation method for cylindrical tubes", J. Mater. Sci., vol. 8, pp. 3158-3165, 2014.

[4] H. Valberg "Extrusion welding in aluminium extrusion", Int. J. Mater. Prod. Technol., vol. 17, pp. 497-556, 2002.

[5] L. Li, H. Zhang, J. Zhou, J. Duszczyk, and G. Y. Li, "Numerical and experimental study on the extrusion through a porthole die to produce a hollow magnesium profile with longitudinal weld seams", Mater. Des., vol. 29, pp. 1190-1198, 2008.

[6] T. Kloppenborg, M. Schwane, N. Ben Khalifa, T. AE, A. Brosius, "Experimental and numerical analysis of material flow in porthole die Extrusion”, Key Eng. Mater., vol. 491, pp. 97-104, 2012.

[7] C. R. Calladine, "Thoery of Shell Structures", Cambridge: Cambridge Univ. Press, pp. 473-542, 1983.

[8] F. Masayasu, T. Takashi, and K. Yasuhiro, "Mathematical models and numerical simulations of a thermally expandable microballoon for plasticfoaming", Chem. Eng. Sci., vol. 104, pp. 220-227, 2013.

[9] S. A. Yonan, M. B. Silva, and P. A. F. Martins, "Plastic flow and failure in single point incremental forming of PVC sheets", Express Polym. Lett., vol. 8, pp. 301-311, 2014.

[10] V. A. Beloshenko, and V. V. Chishko, "Deformation-heat treatment of $\mathrm{Nb}-\mathrm{Ti}$ superconductors using severe plastic deformation methods", Phys. Metals Metallogr., vol. 104, pp. 992$1002,2013$. 
[11] F. Gagliardi, G. Ambrogio, L. Filice, "On the die design in AA6082 porthole extrusion", CIRP Ann. - Manuf. Technol., vol. 61, pp. 231-234, 2012

[12] J. M. Lee, K. B. Min, and K. C. Gil, "Effects of chamber shapes of porthole die on elastic deformation and extrusion process in condenser tube extrusion", Mater. Des., vol. 26, pp. 327-336, 2005.

[13] M. Schwane, F. Gagliardi, A. Jäger, N. Ben Khalifa, and A. E. Tekkaya, "Modeling approach for the determination of material flow and welding conditions in porthole die extrusion with gas pocket formation", Key Eng. Mater., vol. 554, pp. 787-793, 2013.

[14] Y. Sui, W. Zhang, J. Du, "Sectional area optimization subjected to strength constraints for structures combined by multiple elements", J. Beijing Univ. Technol., vol. 33, pp. 112-118, 2007.
[15] B. Liang, J. Yue, "Optimum design of cylindrical shell on stability", J. Mech. Strength, vol. 24, pp. 463-465, 2002.

[16] M. S. Ashhab, T. Breitsprecher, and S. Wartzack, "Neural network based modeling and optimization of deep drawing-extrusion combined process", J. Intell. Manuf., vol. 25, pp. 77-84, 2014

[17] M. Behr, S. Elgeti, M. Nicolai, M. Probst, W. Michaeli, B. Fink, and C. Windeck, "Towards shape optimization of extrusion dies using finite elements", J. Plastics Technol., vol. 6, pp. 411-427, 2009.

[18] W. Michaeli, M. Behr, S. Elgeti, M. Nicolai, M. Probst, B. Fink, and C. Windeck, "Die design automatically optimizing profile dies", Kunstst. Int., vol. 7, pp. 28-30, 2009.

(C) Fang et al.; Licensee Bentham Open.

This is an open access article licensed under the terms of the Creative Commons Attribution Non-Commercial License (http://creativecommons.org/licenses/by-nc/3.0/) which permits unrestricted, non-commercial use, distribution and reproduction in any medium, provided the work is properly cited. 